\title{
A cashless payment transaction (CPaT) using RFID technology
}

\author{
Norsuzila Ya'acob ${ }^{1}$, AzitaLaily Yusoff ${ }^{2}$, Suzi Seroja Sarnin ${ }^{3}$, Darmawaty Mohd Ali ${ }^{4}$, \\ Nani Fadzlina Naim ${ }^{5}$, Murizah Kassim ${ }^{6}$, Nur Amirah Binti Mohd Azni ${ }^{7}$ \\ 1,2,3,4,5,6,7 Faculty of Electrical Engineering,Universiti Teknologi MARA (UiTM), Malaysia \\ ${ }^{1,2,3,4}$ Wireless Communication Technology (WiCoT), Faculty of Electrical Engineering, Universiti Teknologi MARA, \\ Malaysia
}

\begin{tabular}{l}
\hline Article Info \\
\hline Article history: \\
Received Jan 18, 2019 \\
Revised Apr 6, 2019 \\
Accepted May 5, 2019 \\
\hline Keywords: \\
Cashless based system \\
My SQL \\
Parent Monitoring \\
RFID \\
Web-Based
\end{tabular}

\footnotetext{
Norsuzila Ya'acob,

Faculty of Electrical Engineering,

Universiti Teknologi MARA (UiTM) Malaysia,

40450 Shah Alam, Selangor, Malaysia.

Email: norsuzila@salam.uitm.edu.my
}

Corresponding Author:

\begin{abstract}
Virtual money is an actual money that a person own but in a form of a plastic card, an online account and a token or a ticket. Referring to the cash-base system, it is full of fraud and money scam activity. It even happens in a smaller division of a human population which are among family members. For example, when a child decided to do a money scam towards their parents by asking for extra money for what they actually needed to pay for school internal fee and with today's technology, they can easily recreate a receipt of the payment based on the amount of money they have scammed. In this Cashless Payment Transaction (CPaT) in a school based on Low Frequency (LF) RFID Technology system, the system offers a virtual money transaction in the plastic card form and allows the transaction to be monitored by parents with the help of Radio Frequency Identification (RFID) technology, MySQL database and Email notification system. The MySQL database is paired with the PHP prgramming language where the calculation for deduction credit will be done before being updated to the RFID card and MySQL database. As a result, the system will allow a cash-free transaction for school payment activity and allow parents to monitor their child spending activity and nutrition intake via MySQL database that are designed based on Graphical User Interface (GUI) within one minute after the transaction is successfully done.
\end{abstract}

Copyright $(2019$ Institute of Advanced Engineering and Science. All rights reserved.

\section{INTRODUCTION}

The e-banking revolution, according to [1], is a tool for banks to attract and retain customers [2]. It is related to the competition among commercial banks, where consumers have the ability to become bankers, since diversity in e-banking for consumers is beyond conventional banking boundaries [3-5]. A secured and convenient way of making payments is the cashless transaction. Cashless transactions are way of making payments without the use of physical cash, a gateway to technological advancement in the field of world economy [6]. A cashless payment is a behavioural change in the people where people eliminate usage of money as a medium of exchange for goods and services by allowing electronic transfer payments or non electronic payment via cheques [7]. Most of the research [8], suggests that even though cashless payments are growing rapidly across the world, hard currency remains resilient. By adopting electronic payment system an economy leads to a cashless society. Cashless payment might have a positive impact on economic activities [9] but it also provide an opportunity for corruption [10], caused bankruptcy among youth and reduced policy control of the monetary system [11]. Others research is about adoption of mobile payment services. The rapid adoption of mobile phones and their role in the development of personal and professional activities has been one of the 
most important technological events in recent decades [12]. There is abundant international research focusing primarily on the factors that influence the adoption of mobile payment services [13-15] however, evidence is almost non-existent to suggest that similar studies have been conducted in an emerging market such as that of South Africa.

The technological advancement has coincided with currency reform throughout human history. The advent of writing in early Mesopotamia provided new ways to number commodities, forming the basis of accounting [16]. This finding has allowed the human population today to experience virtual money system. Virtual money system is a new beginning towards a futuristic school environment. Therefore, the Cashless Payment Transaction (CPaT) in a school based on Low Frequency (LF) RFID Technology offers a system that totally utilized the advantage of virtual money with the help of RFID technology. RFID is a short form for Radio Frequency Identification. It operates at different frequency band or spectrum depending on its type. To allow a transaction activity with secure principle, it is advisable to use a Low Frequency RFID (LF RFID) [17]. A LF RFID operates at $125 \mathrm{kHz}$ of frequency. It is advisable due to the fact that a contactless transaction needed to be in a close range of transaction to avoid any scam acted upon it [18]. LF RFID offers a short-range reading and it works best on item tagging. Moreover, it is supported by multiple international and industry standard. Thus, conclude that the utilization of it can be maximized. In this project, RFID technology is used as the medium to make every transaction took place at school to replace the cash-based system with a cashlessbased system.

A cashless-based system is a system that allows a transaction to happen without the presence of actual money. It is also equipped with Automated Data Collection (ADC) system, where for every transaction happened, everything will be recorded thoroughly in the database system. ADC is a system that automatically collects the required details and stores it in the manner as it was programmed [19]. This helps user to monitor their money flow in an organized manner. In advance, the database system also allows user to have access to it at anytime and anywhere. Looking back to the school environment, the person who will be interested in monitoring the money flow is the students' parents. Thus, the implementation of CPaT to school environment will allow parents to have access to their children finance activity and even their nutrition activity as CPaT will record thoroughly for every activity being acted upon.CPaT is a system that featuring a virtual cash in school implementation with an accurate transaction and data collection. Moreover, it offers a secure transaction process due to it operates in low frequency that enable a transaction to be made only in a short range of distance [20]. The objective of this project is to implement a cashless system towards students at school level with the help of LF RFID technology and database system.

\section{RESEARCH METHOD}

This cashless monitoring system is designed to help parents monitor their child financial activities. The current transaction system used among school student is a cash-based system, which means, all transaction happen is by using actual money. This system has caused numbers of problem. Thus, CPaT were invented to overcome the problem that may arise. CPaT offer both automatic and manual approach to pay, which for automatic approach, student were needed to flashed their RFID card, while for manual approach, student were required to enter their card number. Figure 1(a) below shows the overall system for both automatic and manual approach.

It begins with the student choosing an item to purchase or to do transaction for any internal school fee (i.e. PIBG fee). Once the item has been chosen, student will flash their card to RFID reader (automatic approach) or the student will key in their card number (manual approach) to make payment for the chosen item. Next, the system will read the card or the key in number and collect the payment via the credit hold by the card number. The transaction is successful if the card has enough credit. A successful transaction will result in data uploaded to the MySQL database, current credit will be deducted according to the item price and current credit will be updated in both card and database. Once the database updated the current credit, it will compare the current credit with credit limit (i.e RM5.00). If the credit has not reached the credit limit, no action took place. However, when the transaction is failed or unsuccessful, two conditions applied. First, the card is not flashed correctly, the student will need to reflash their card to the reader. Second, if the card has not enough credit, an Email will be sent to student parents. Parents will transfer credit to student card via online transfer system using the parent device with internet connection. Lastly, the student can proceed to do the transaction.

The figure 1(b) shows the topup flowchart. It begins with parent selecting the topup button. The topup button will let parent choose which child to be topup. Once the child has been selected, the amount to be topup were needed to be selected (i.e. RM 5.00, RM 10.00, etc). Lastly, once parents are comfirmed by the selected amount, the topup amount will be added to student card id automatically. The impotance if this system are to allow an on going monitoring activity, where parents can monitor their child spending and nutrition intake at anywhere and anytime. Moreover, it also allows parents to have access to their child current account status 
with the help of email notification. The email notification will be sent to parents once the system detecting an insufficient amount of credit from student card Id. Next, parents can easily add a topup to their child card via online credit transfer. All data of child spending activity including topup from parents' sre stored in the history page in the MySQL database. Next, the data stored in the database is fetched to webpage via php script and can be view by parents at anywhere and anytime.

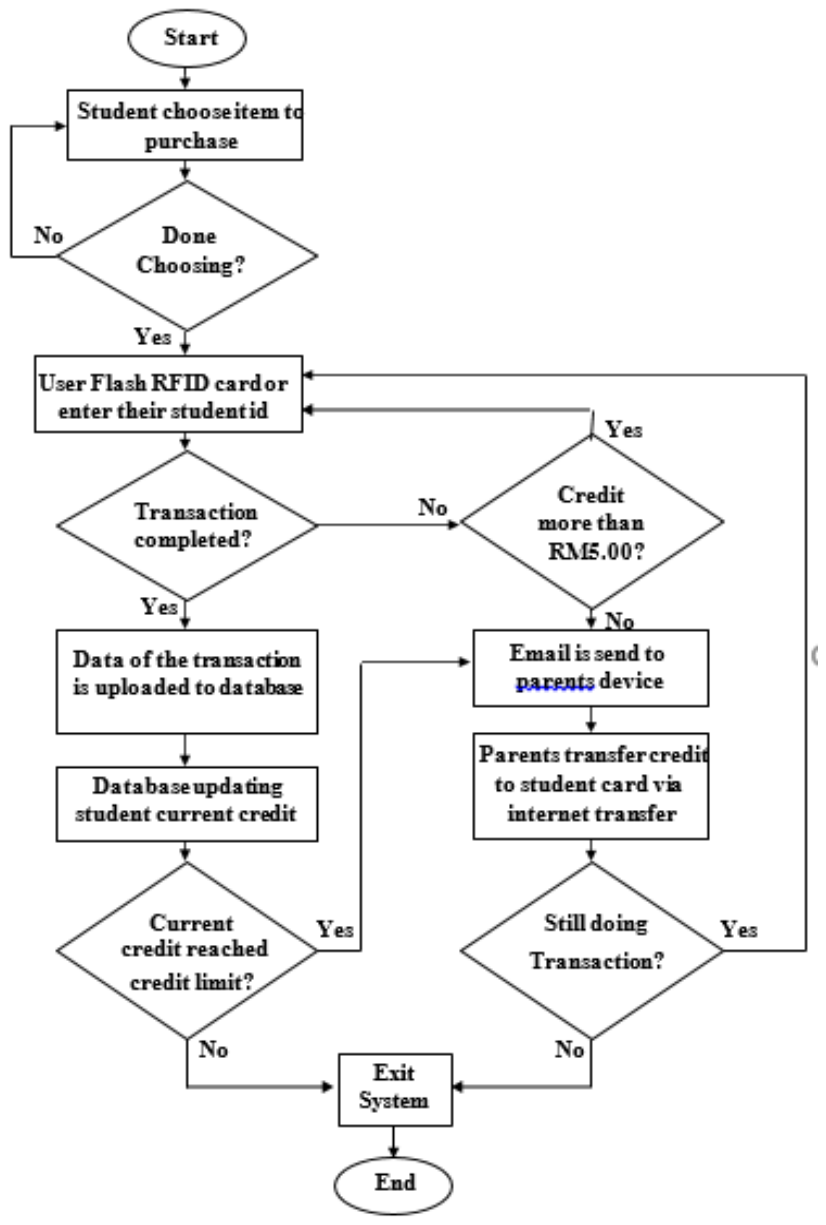

(a)

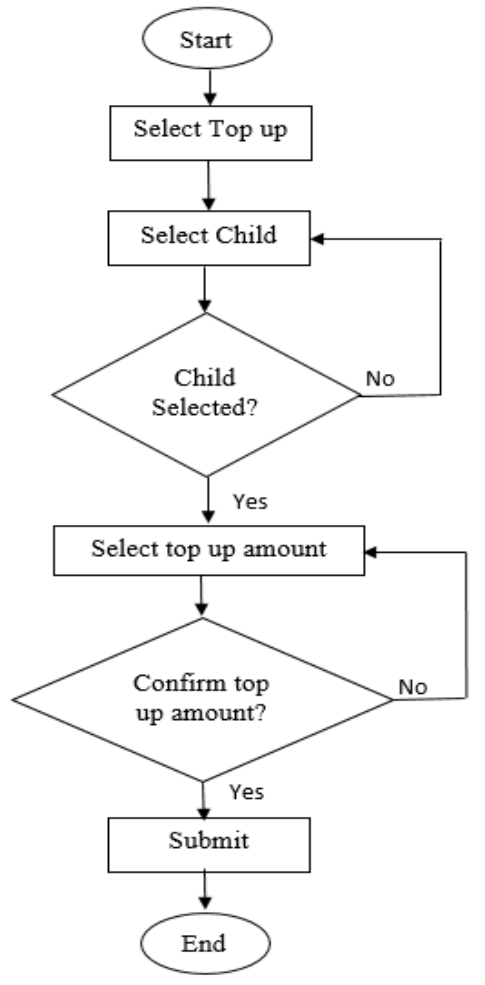

(b)

Figure 1. (a) Flowchart of the overall system and (b) Top up flowchart

In this system, the hardware part is focusing on the RFID reader, RFID card and keyboard. Where only student is owned a RFID card. The card will be flashed to RFID reader or student enter their student ID via keyboard as manually to make a transaction. The software part of the system involves the MySQL database, the Xampp Server and the notepad++ software. The webpage is designed and developed with the help of notepad++ software, where all coding is written and tested. The coding are the combination of PHP language and Hypertext Markup Language (HTML) [21]. Once the code is completely written, the file is saved in php format before it can be display using XAMPP localhost server. To test the webpage, a localhost server is needed. This system uses xampp localhost server as the platform to display the webpage. XAMPP is a free and open source cross-platform web server developed by Apache Friends and interpreters for PHP language script [22]. The localhost will fetch needed file to be displayed on the webpage under the file name xampp.

As referred to the database used, phpMyAdmin were chosen due to a free software tool written in PHP language, intended to handle the administration of MySQLover the Web [23]. The phpMyAdmin supports a wide range of operations on MySQL and MariaDB. Frequently used operations in managing databases, tables, columns, relations, indexes, users, permissions and can be performed via the user interface, while user still have the ability to directly execute any SQL statement [24]. 


\section{RESULTS AND ANALYSIS}

CPaT system involves both hardware and software in the process of developing it. Software is the sequence of codes or instructions, while hardware is a tool, machinery, and other durable equipment used as a physical identity to interpret software action [25]. The system begins with choosing user interface. As shown in Figure 2, the user was given two choices which are to enter the system as a seller or parent. Once the user has chosen their login selection, the user will be brought to a login page.

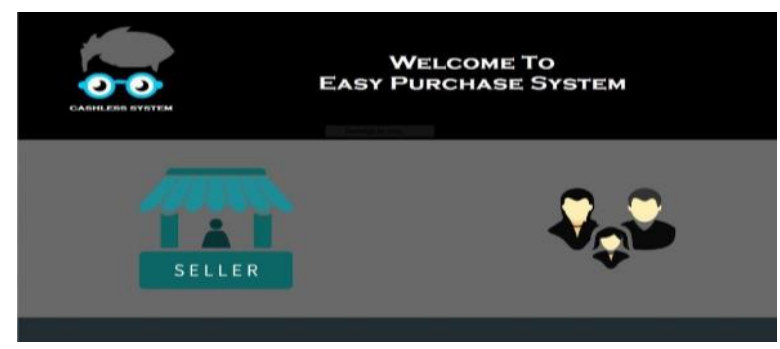

Figure 2. User selection interface

\subsection{Seller Interface}

Once clicking a seller login icon, the user will enter the system as the seller. Here, users will be brought to seller login page as shown in Figure 3(a). The login page requires the user to enter a valid username and password or register an account as shown in Figure 3(b). After successfully creating an account, user will be brought back to login page to enter a registered username and password before the user can have access to the seller system.

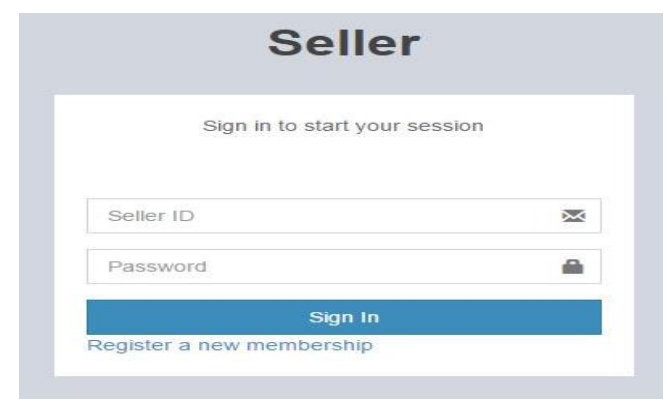

(a)

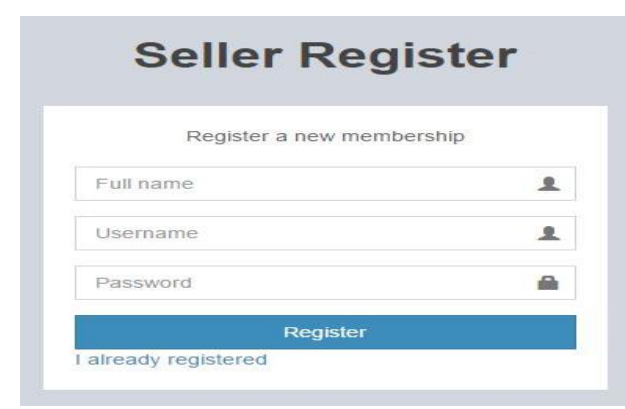

(b)

Figure 3. (a) Seller login page and (b) Seller registration page

After successfully login into the system, user will be brought to seller dashboard page. Here, userwas displayed with the list of item that are available in the seller system as shown in Figure 4(a). On the left side of the page, user is displayed with tab page selection as shown on Figure 4(b). The tab page selection will bring user to dashboard and transaction page accordingly.

As for the Transaction tab, users will be brought to the transaction page as shown in Figure 5. Here, the user will click the scan product button located at the bottom right of the page to add item into the cart. Once the button is clicked, Figure 6 (a) is displayed for the user to choose an item to be added to cart. Lastly, if the submit button is pressed, Figure 5 will be updated with items to be bought. If nasi goreng was chosen, the subtotal, tax, and total price of the chosen item is as shown in Figure 6(b). Now, there are two conditions apply, whether to proceed with making payment by clicking the submit payment button that are located next to the scan product button or cancel the transaction by clicking the cancel button that are located on the left side of the page. 


\section{Dashboard version 2.0}

List of item

\begin{tabular}{|l|l|l|}
\hline ID & Name & Description \\
\hline 1 & Nasi Goreng & Nasi yang digoreng \\
\hline 2 & Air Limau & Air ini berperisa limau \\
\hline
\end{tabular}

(a)

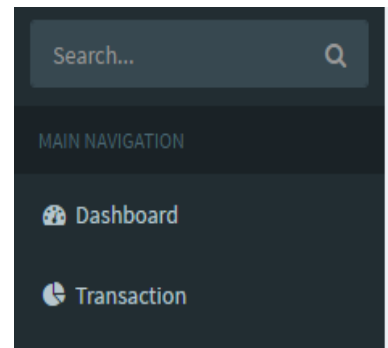

(b)

Figure 4. (a) List of items and (b) Tab page selection

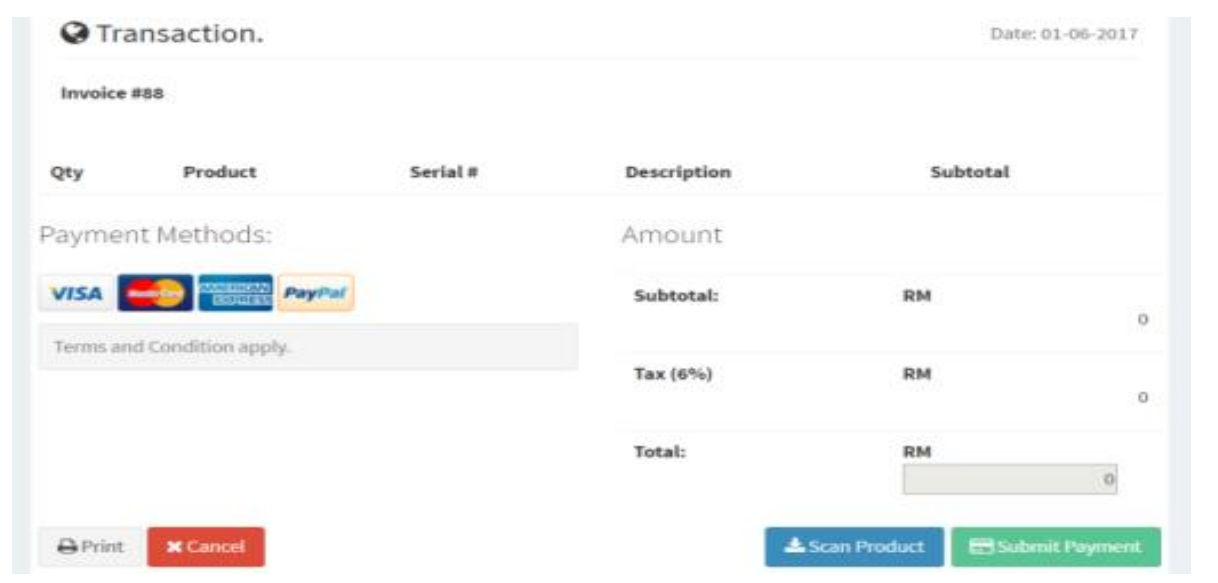

Figure 5. Transaction page

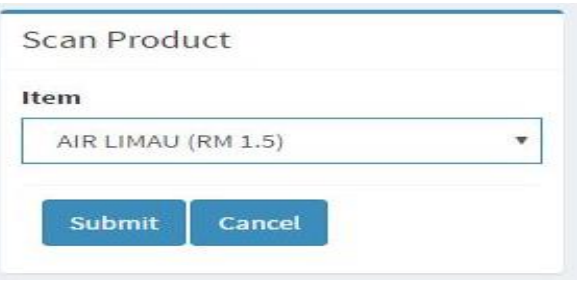

(a)

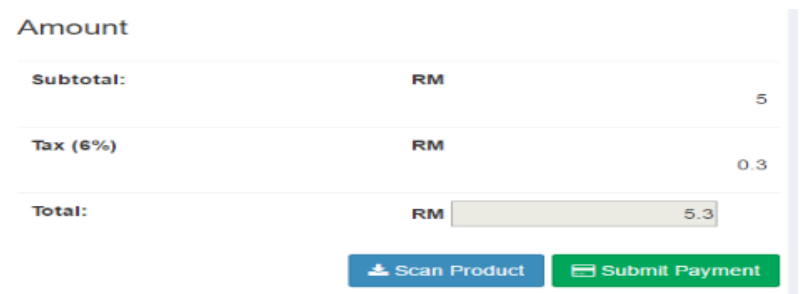

(b)

Figure 6. (a) Scan product page and (b) Amount of payment

Once the submit payment button is pressed, Figure 7(a) will popup. Here is when the automatic or manual method of detecting student id applies. If the students' card is available, they can simply flash their card to the RFID reader, and the system will automatically detect their students' ID. Else, the user will key in the student's id manually. If the id is valid and the card has a sufficient amount in it, the green notification in Figure 7(b) will be displayed on top of the page. However, if the id is invalid and the card has an insufficient balance, red and orange notification will be displayed.

If the system detects a sufficient amount, the user may click the submit button as shown in Figure 7(a) to proceed with payment. However, if the system detecting an insufficient amount, it will send an email to parents to acknowledge parents about their child's current account balance as shown in Figure 8 . 


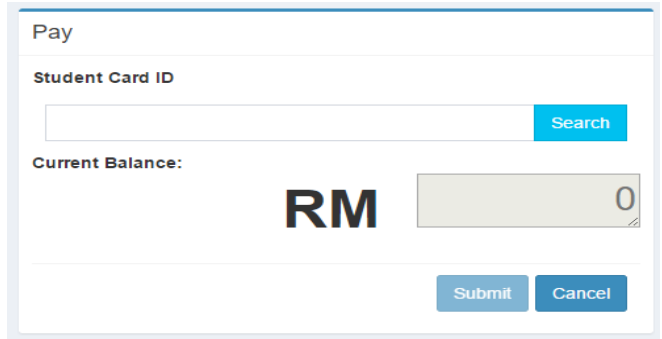

(a)

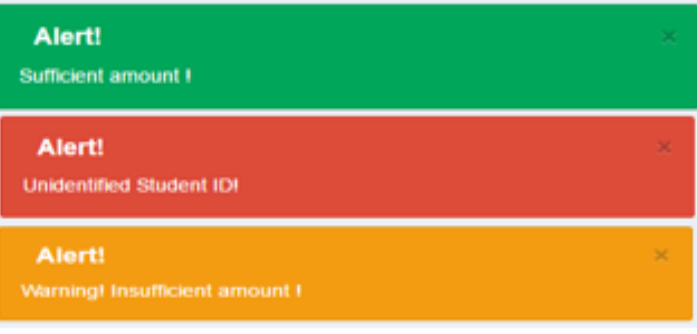

(b)

Figure 7.(a) Submission payment page and (b) Amount Notification

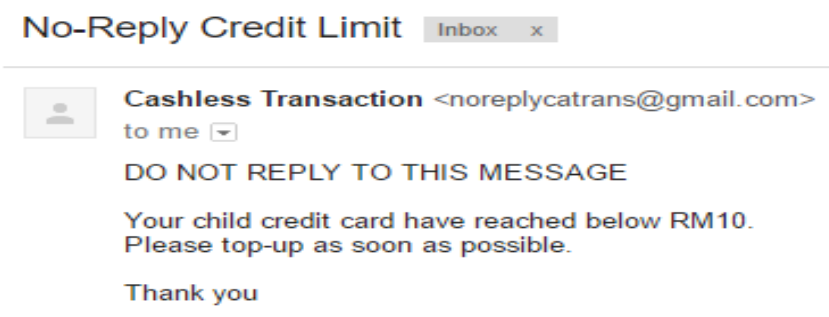

Figure 8. Parent email notification

\subsection{Parent Interface}

Here, once user click at parent login icon, the user will enter the system as the parent. Here, users will be brought to parent login page as shown in Figure 9(a). The login page requires the user to enter a valid username and password or register an account as shown in Figure 9(b). After successfully creating an account, users will be brought back to login page to enter a registered username and password before the user can have access to the parent system.

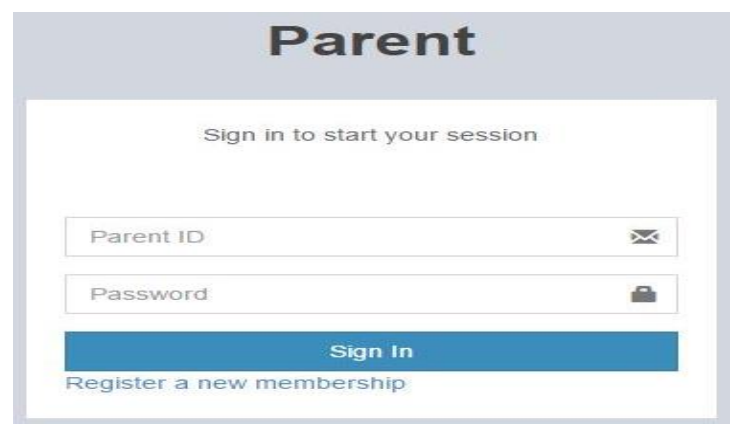

(a)

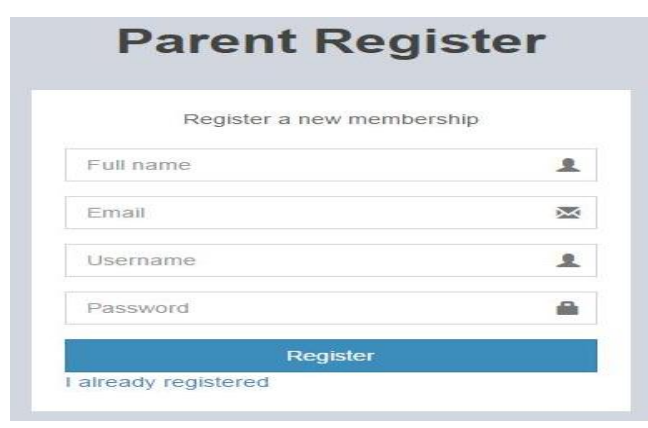

(b)

Figure 9. (a) Scan product page and (b) Amount of payment

After successfully loging into the system, users will be brought to the parents' dashboard page as shown in Figure 10(a). Here, the user was displayed by the child monthly spending graph, child card balance and current month usage as shown in Figure 10(b). On the left side of the page, the user is displayed in the tab page selection as shown on Figure 10(a). The tab page selection will bring users to dashboard, Topup, History and register child page accordingly.

Figure 10(b) shows the content of the parent dashboard. On top of the page, a graph of the child monthly usage is recorded. The displayed graph will display a usage history for at least seven months. Next, on the bottom left of the page, child current month usage is displayed. Lastly, on the bottom right of the page, the child card balance will be displayed. The maximum amount of a card can hold is RM 200. Everytime a 
transaction is made, both child current month usage and card balance will be automatically updated to the dashboard. As mention earlier, the dashboard tab will display Figure 10(a). The first thing that user need to do is to register their child into the system by clicking the register child tab. Here, users will be brought to register child page as shown in Figure 11. User were needed to fill in some information about their child. Lastly, press submit to complete the registration process.

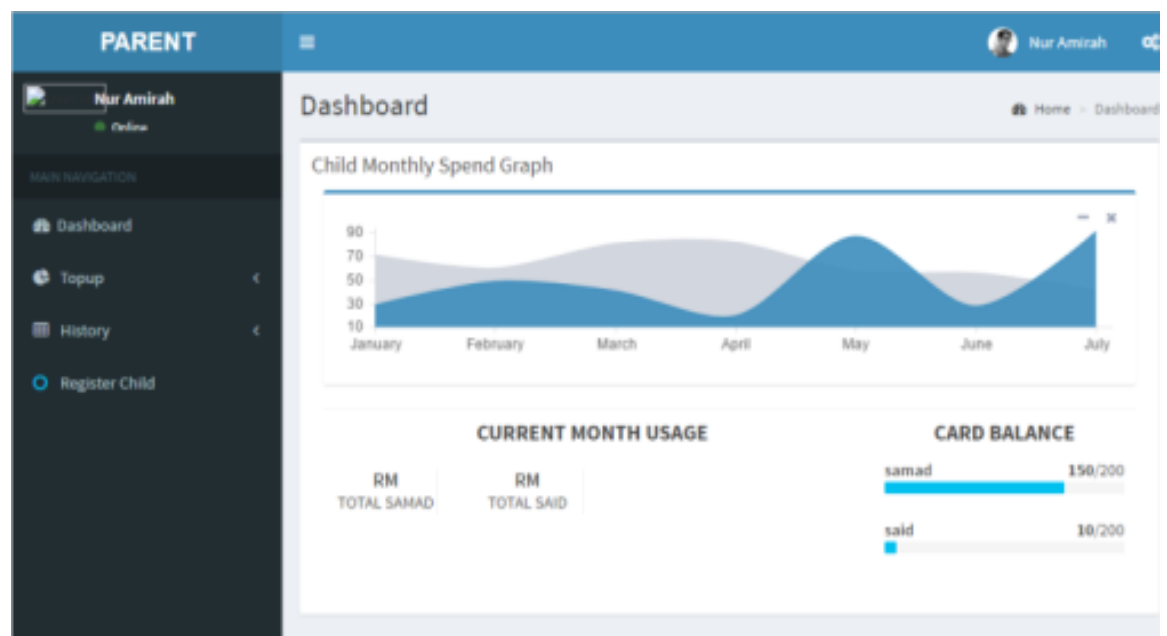

(a)

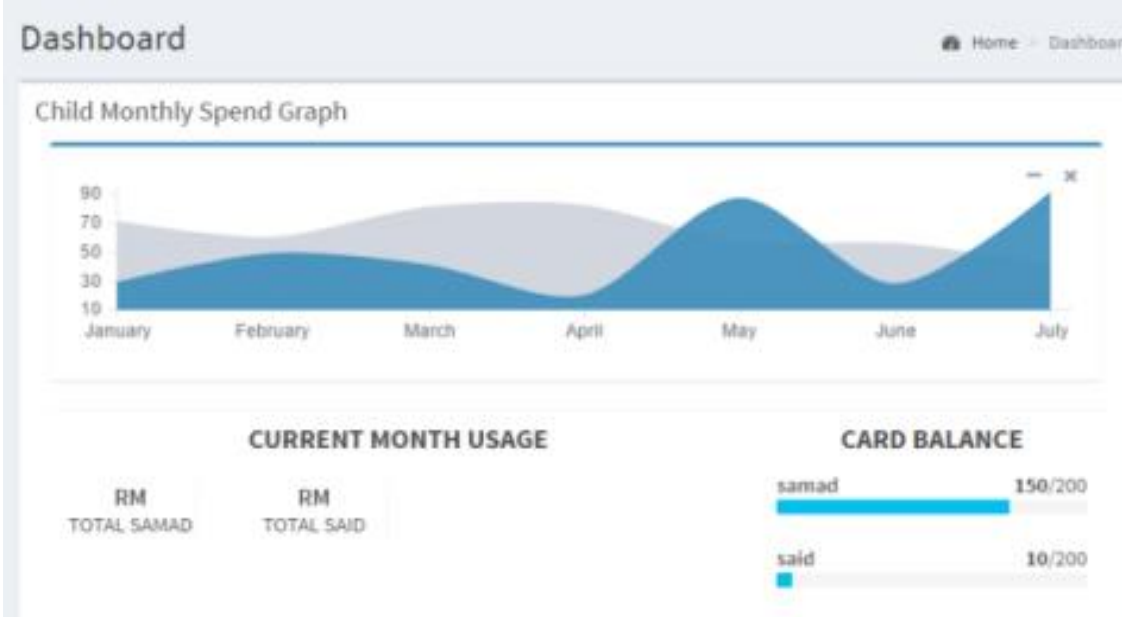

(b)

Figure 10. (a) Scan product page and (b) Amount of payment

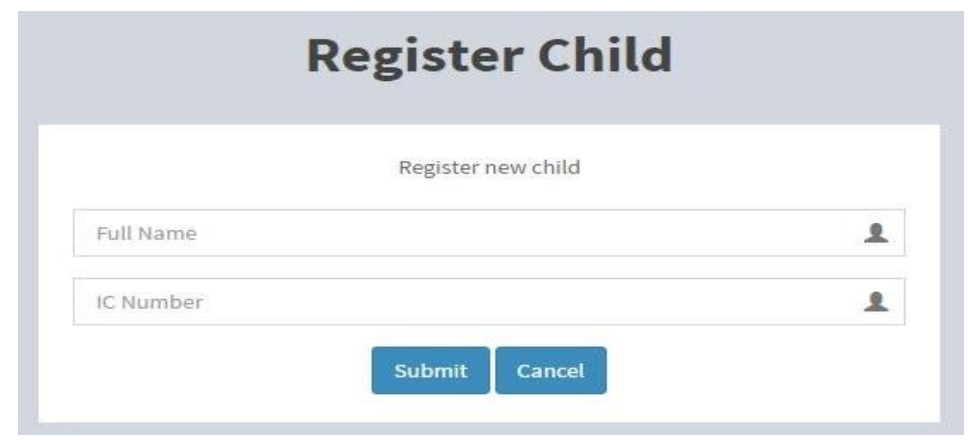

Figure 11. Parent registration page 
Next, after successfully register a child, the Topup tab will brought user to option of which child to be topup as shown in Figure 12(a) and once user has select a child, the system brought user to the topup page as shown in Figure 12(b). Here, user can choose the amount to be added to the selected child account (i.e. RM5.00). Next, user may proceed by clicking the submit button. If the amount to be topup has exceed the maximum amount of the account which is RM 200, the system will pop up an alert notification to inform the card is reach maximum amount and the topup process will be discard. Else, the topup will be added to student current balance, and here, only the card balance in the dashboard page will be updated.

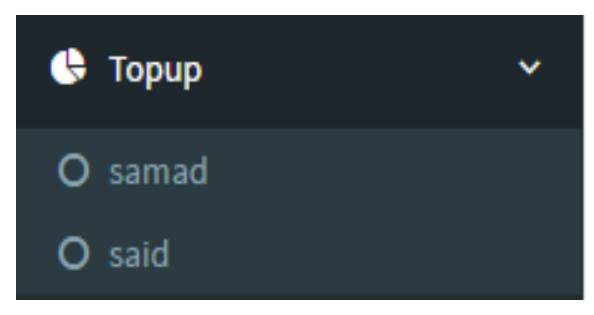

(a)

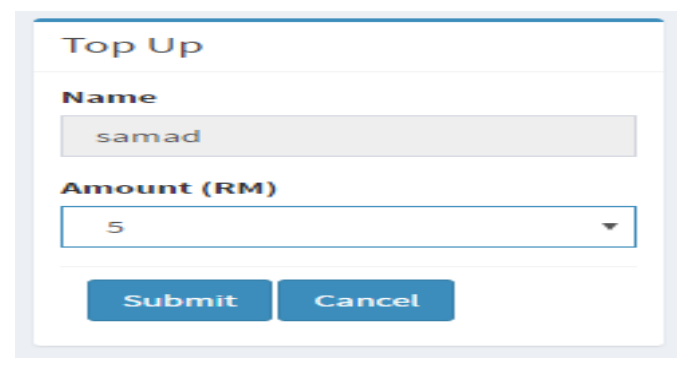

(b)

Figure 12. (a) Child to be topup option and (b) Topup amount selection page

Lastly, all transactions took place in the seller interface (i.e. from the transaction page) and transaction from parent interface (i.e. from the topup page) is summarized and recorded in the history page. The user simply click the history tab to choose which child history to be viewed, and Figure 13 is displayed all transactions made for the whole month.

\begin{tabular}{|c|c|c|}
\hline Date & Item & Price (RM) \\
\hline 2017-05-11 & NASI GORENG & 5 \\
\hline 2017-05-11 & AIR LIMAU & 1.5 \\
\hline 2017-05-17 & Card was topup & 5 \\
\hline 2017-05-17 & Card was topup & 100 \\
\hline 2017-05-17 & Card was topup & 100 \\
\hline
\end{tabular}

Figure 13. Exceed maximum card amount notification

\section{CONCLUSION}

This paper presents a cashless system towards students at school level with the help of LF RFID technology and database system. Generally, this Cashless Payment Transaction (CPaT) in school based on LF RFID Technology is a cashless-based system that allows a transaction to happen at the school environment via virtual money. CPaT is designed to replace the use of actual cash with virtual cash and allow parents to monitor their spending through the transaction data that has been uploaded to the database every time a transaction took place. The system will automatically calculate the current credit left inside the card and alert parent via Email notification once the current credit has reached and pass the credit limit (i.e. RM5.00). Parents will choose to transfer credit to student card through internet transferring or choose to ignore the alert. Once a credit has been transferred, students can continue to do other transaction. There are few recommendations can be added to future implementation of $\mathrm{CPaT}$ system which are, record the data in a bar chart or pie chart manner for a better data analyzation purpose, provide a Short Message Service (SMS) notification to replace the Email notification method as the Email method requires internet connection to operate, which cause some limitation for users to get a real time notification. Moreover, the system can also be improved by creating a mobile-base application. Where, users will have access to all information in a single application. 


\section{ACKNOWLEDGEMENTS}

The authors would like to thank Faculty of Electrical Engineering, Universiti Teknologi MARA (UiTM) for their valuable support. This research is partly funded by the Malaysian Government through UiTM under 600-RMI/DANA5/3/BESTARI (122/2018).

\section{REFERENCES}

[1] Sharma, H, "Bankers Perspectives on E-Banking", National Journal of System and Information Technology. Vol 1, no. 1, pp. 71-85, 2011.

[2] Rajendran, R.P., Suresh, J., "Customer Satisfaction Index as aPerformance Evaluation Metric: A Study on Indian EBankingIndustry”. International Journal of Business, vol 22, no. 3, pp. 251-274, 2017.

[3] Sabharwal, M., "Multi-modal Biometric Authentication and SecureTransaction Operation Framework for EBanking”. International Journal of Business Data Communications and Networking, vol 13, pp. 1, pp. 102-116, 2017.

[4] Wang, M., Cho, S., Denton, T.,'The Impact of Personalization and Compability with Past Experience on E-Banking Usage", International Journal of Bank Marketing, vol 35, no 1, pp. 45-55, 2017.

[5] Sachdeva, K., Kumar, P.S., "Impact of E-Banking on the Performance of Commercial Banks in India: A Panel Data Approach”. International Journal of Applied Business and Economic Research, vol 15, no. 9, pp. 55-67, 2017.

[6] Dr Neetu Kumari1, Jhanvi Khanna, "Cashless Payment: A Behaviourial Change to Economic Growth". International Journal of Scientific Researc and Education, vol.5, Issue.7, pp.6701-6710, 2015

[7] Tee, Hock Han and Hway-Boon Ong, "Cashless Payment and Economic Growth”, Financial Innovation, Vol.2, No.4, pp 1-9, 2016.

[8] Premchand A. and A. Choudhry, "Future of Payments - ePayments\|", International Journal of Emerging Technology and Advanced Engineering, Vol. 5, pp. 110-115, 2015.

[9] Hasan I, De RT, Schmiedel H, "Retail Payments and Economic Growth", Bank Finland Research, pp 1-37, 2012.

[10] Park J., "Corruption, Soundness of the Banking Sector, and Economic Growth: A Cross- Country Study", International Journal of Money and Finance, Vol. 31, pp. 907-929, 2012.

[11] Ezuwore-Obodoekwe CN, Eyisi AS, Emengini SE, Chukwubuzo AF, “A Critical Analysis of Cashless Banking Policy in Nigeria", IOSR Journal of Business Management, Vol. 16, pp 30-42, 2014.

[12] Liébana-Cabanillas, F., De Luna, I. R., \& Montoro-Ríos, F. J., "User behaviour in QRmobile-payment system: The QR payment acceptance model”. Technology Analysis \& Strategic Management, vol 27, no. 9, pp. 1031-1049, 2015. doi:10.1080/09537325.2015.1047757

[13] Chong, A. Y. L., Chan, F. T. S., \& Ooi, K. B., "Predicting consumer decisions to adopt mobile commerce: Crosscountry empirical examination between China and Malaysia". Decision Support Systems, vol 53, pp. 34-43, 2012. doi:10.1016/j.dss.2011.12.001

[14] Mallat, N., "Exploring consumer adoption of mobile payments - A qualitative study", The Journal of Strategic Information Systems, vol 16, 413-432, 2007. doi:10.1016/j.jsis.2007.08.001

[15] Pham, T. T. T., \& Ho, J. C. "The effects of product-related, personal-related factors and attractiveness of alternatives on consumer adoption of NFC-based mobile payments", Technology in Society, vol 43, pp. 1-16, 2015.

[16] Smith A. "Future of Money: Classifying Virtual Currency Systems", Retrieved December 20, 2016 from http://bigthink.com/hybrid-reality/future-of-money-classifyingvirtual-currency-systems, 2009.

[17] Intermec "UHF vs. HF RFID vs LF RFID: New Insight on the Old Debate" Intermec Technologies cooperation, 2007.

[18] Jaesik Lee, et al., "Secure Quick Response-Payment(QR-Pay) System using Mobile Device” Dept. of Computer Science, SoongSil University, Seoul, South Korea, 2011.

[19] Kim, C, Tao, et al., "An Empirical Study of Customers' Perceptions of Security and Trust in e-Payment Systems", Electronic Commerce Research and Applications, vol. 9, no. 1, pp. 84-95. 2010.

[20] Hsieh, "E-Commerce Payment Systems: Critical Issues and Management Strategies", Human System Management, vol. 20, no.2, pp.131-8, 2014

[21] Don Ho, "About Notepad++" Retrieved May 20, 2017 from https://www.apachefriends.org/index.html

[22] Roberto Vergallo "IDA-Pay: an innovative micro-payment system based on NFC technology for Android mobile devices" Department of Engineering for Innovation University of Salento Lecce, Italy, 2012.

[23] SoonduckYoo, et al., "The supplier management and approval in reverse trade card, an electronic payment system on the B2B" Dept. of IT, University of Hansei, Korea, 2010.

[24] Shafiqur Rehman, et al., "Towards An Easy To Pay System (ETPS) For Ecommerce" Department of Computer Science Sukkur Institute of Business Administration Sukkur, and Pakistan National University of Computer and Emerging Sciences Karachi, Pakistan, 2009.

[25] Mustaffa Samad, Yusnani Mohd Yusoff, "Computer Organization and Architecture Fundamentals” Pearson, pp. 39, 2016. 